\title{
Facilitating innovation in FinTech: a review and research agenda
}

\author{
Ahmad Alaassar ${ }^{1,2,3} \cdot$ Anne-Laure Mention ${ }^{2,4,5,6} \cdot$ Tor Helge Aas ${ }^{3}$ \\ Received: 10 June 2021 / Accepted: 29 January 2022 / Published online: 11 February 2022 \\ (c) The Author(s) 2022
}

\begin{abstract}
The purpose of this paper is to carry out content analyses on the existing literature to investigate the knowledge state of innovation facilitators adopted to promote financial innovation. In total, 56 papers were analysed using the NVivo software package. Three categories of innovation facilitators emerged from the literature capturing the perspective of regulators, incumbents and new entrants. Each identified instrument is defined and its processes and implications described. Many initiatives were led by regulators, revealing a regulatory strategy change from risk-based to opportunitybased regulation, with regulatory sandboxes being the most commonly adopted instrument. Incumbent-led innovation facilitators were also identified and typically took the form of corporate incubation models, co-working spaces, venture funds and innovation platforms to support financial institutions with partnerships, acquisitions or self-development. Lastly, the literature review revealed innovator-led instruments to support start-ups with raising capital. Based on our results, we discuss several important observations and propose avenues for future research capturing each of the identified perspectives. This paper contributes to incubation research and the financial innovation and FinTech literature streams.
\end{abstract}

Keywords Financial innovation · FinTech · Innovation facilitators · Incubation models $\cdot$ Literature review $\cdot$ Research agenda

JEL Classification G2 $\cdot \mathrm{L} 26 \cdot \mathrm{M} 13 \cdot \mathrm{O} 16 \cdot \mathrm{O} 3$

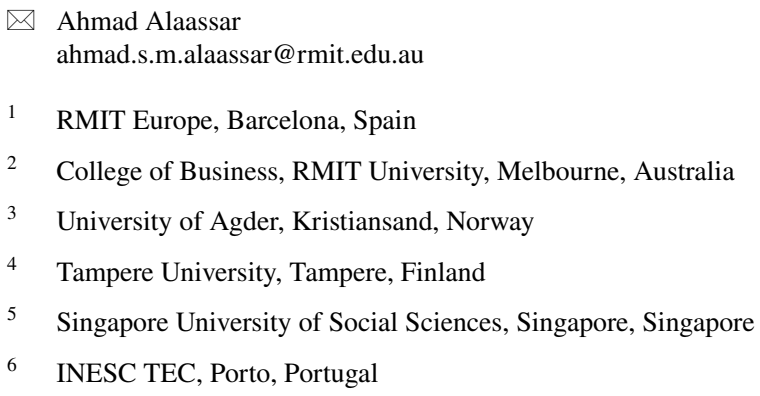




\section{Introduction}

Financial markets are crucial for the stability of economies (Mention and Torkkeli 2012). Financial services offered in this sector include identity and value authentication, value transfer, value storage, value lending and value investment and financing (Hendershott et al. 2021). In this context, enabling technologies such as artificial intelligence and blockchain have recently provided abundant opportunities for entrepreneurial entry (Berman et al. 2021) and financial innovation, defined as 'the act of creating and then popularizing new financial instruments, as well as new financial technologies, institutions, and markets' (Lerner and Tufano 2011 , p. 6). In the late 1970 s, financial innovation was measured by the number of financial patents (Miller 1986), whereas in the early 1990s, the share of expenses financial institutions spent on information technology was used to indicate the level of innovation in financial markets (Scott et al. 2017). Despite the introduction of prominent innovations such as automated teller machines (ATMs) and internet banking systems, the financial sector was not perceived as innovative (Hornuf et al. 2020; Lerner et al. 2016). However, after the global financial crisis in 2008, this changed dramatically with the rise of financial technology (FinTech) innovations, which have revolutionised the collaboration and competition dynamics among both new entrants and incumbents and forced regulators to adapt and evolve (Berman et al. 2021; Lee and Shin 2018; Zetzsche et al. 2017). The evolution of the banking industry over the past three decades was examined by Hanafizadeh and Marjaie (2020), whose results reveal that financial crisis and competition are the newest areas of focus in the literature.

To purposefully broaden the scope of this review to include newcomers, established firms and regulatory changes, FinTech is defined as 'technology-enabled innovation in financial services that could result in new business models, applications, processes or products with an associated material effect on the provision of financial services' (Financial Stability Board 2017, p. 7). Empirical research investigating financial innovation in the FinTech era is, however, still in its early stages. For example, when considering the governance of financial innovation, the literature (e.g., Arthur 2017) informs us of the regulation-innovation lag, which provides financial innovation stakeholders the time to identify, assess and mitigate any risks that may emerge. Along these lines, it is also noted that the ability to contain all risks is limited at best; hence, complementary instruments are required to better manage uncertainties (Arthur 2017). This is particularly important given the novel characteristics of FinTech innovations, which use large amounts of varied types of data, automate algorithmic programs through enabling technologies and disintermediate financial solutions (Brummer and Yadav 2019).

Despite the advantages of technology-enabled financial innovations including efficiency, decentralisation, transparency and security (Hendershott et al. 2021), negative implications for the financial stability of economies due to micro- and macro-level financial risks may emerge. To date, however, there are limited data assessing the significance of FinTech implications on financial stability (Vucinic 2020). That said, the underlying liability of novelty for entrant FinTechs may be 
rooted in regulatory constraints, including unclear regulation and the high compliance costs involved in acquiring financial licenses (Arner et al. 2015; Haddad and Hornuf 2019). As a result, regulatory uncertainties may discourage investment and make it difficult for FinTech start-ups to access capital (Cornelli et al. 2020; Mention 2019). Similarly, financial innovation increasingly provides unprecedented challenges for regulators trying to monitor FinTech activity (Allen 2019). To overcome the risk implications and regulatory hurdles for regulators and newcomers, respectively, the emerging FinTech literature has investigated regulatory responses to financial innovation, revealing a transition in regulators' approach from a wait-and-see to a test-and-learn standpoint (Arner et al. 2015; Buckley et al. 2020a). Most prominent test-and-learn approaches include regulatory sandboxes, innovation hubs or labs and accelerators that enable varying degrees of engagement and experimentation (Ahern 2020). These instruments promote the exchange of technological and regulatory knowledge among both regulators and innovators (Alaassar et al. 2020; Zetzsche et al. 2017). More recent empirical investigations have found that sandboxes significantly increase the probability of raising capital as a result of reduced regulatory hurdles and information asymmetry problems (Cornelli et al. 2020; Goo and Heo 2020). Similarly, we also find studies on responses initiated by incumbents and newcomers (Berman et al. 2021). That said, the literature investigating instruments that facilitate FinTech innovation activities is both nascent and fragmented across research fields. Despite ongoing efforts (e.g., Brummer and Yadav 2019) that make key contributions by reviewing regulatory responses to financial innovation, they remain limited in scope, capturing only limited regulatory jurisdictions from a legal perspective within law research fields. In a like manner, other research streams may have investigated incumbent responses and their potential repercussions on market conditions, though often through an economics or finance lens (e.g., Redmond 2013). As such, there is a lack of unified investigations of these perspectives through a management lens. The present study helps fill this void by synthesising the existing literature on regulatory, incumbent and entrepreneurial initiatives promoting FinTech innovation activities and provides an agenda to pave the way for future research.

This review conceptualises innovation facilitators ${ }^{1}$ as instruments that support FinTech innovation activities in terms of business creation and development, regulatory guidance and compliance, testing financial solutions and collaborating with public and private stakeholders in financial markets. The creation and amendment of regulatory frameworks and laws goes beyond the scope and research field of this study, which is situated within management research. Specifically, we explore which innovation facilitators exist, define them, describe their activities and review their impact on financial innovation. Based on the nature of this review, we link this study

\footnotetext{
1 Innovation facilitator is a label commonly employed by the European Commission and associated institutions to represent innovations hubs, regulatory sandboxes and other instruments that promote FinTech innovation activities (Kapsis 2020; Tanda and Schena 2019). We extend this broad term to encompass not only government-led instruments but also those employed by incumbents and new entrants.
} 
to the incubation literature stream, which investigates the role of support instruments in enabling the creation and growth of new ventures (Pauwels et al. 2016). Alaassar et al.'s (2021a) recent contribution explores the role of regulatory sandboxes as an incubation model in the FinTech context.

This paper addresses three research questions:

RQ1: What are the FinTech innovation facilitators established in the banking industry?

RQ2. How are the identified innovation facilitators functioning?

RQ3. What impact do these facilitators have on financial innovation?

To answer these questions, we conduct a literature review (LR; Tranfield et al. 2003) and use the NVivo software package to conduct content analyses (Adams et al. 2017; Gaur and Kumar 2017; O'Kane et al. 2021). After search refinement, 56 research studies were identified and further analysed using deductive and inductive approaches. While we acknowledge the contribution of existing review studies (e.g., Brummer and Yadav 2019), to the best of our knowledge, no previous reviews have synthesised the literature on FinTech innovation facilitators and captured their processes and consequences on a global scale from multiple perspectives including regulators, incumbents and new entrants. In addition, most contributions to date remain conceptual and discuss the implications of FinTech for financial markets in relation to specific issues such as compliance with legislative requirements (e.g., anti-money laundering and anti-fraud measures), regulation of crowdfunding and initial coin offerings (ICOs), regulatory technology (RegTech) to enhance regulatory processes, investor and consumer protection or risk to financial stability rather than focusing on supportive instruments.

This paper is structured as follows. Section 2 begins by reviewing the incubation literature and its linkages to the FinTech research stream. Section 3 presents the method applied and the methodological choices made during this review. Section 4 presents the results, which are discussed in Sect. 5 relative to the research questions, highlighting several important observations from which a research agenda is derived. Additionally, theoretical and practical implications are presented here. Finally, Sect. 6 concludes with research limitations.

\section{Literature background: incubation research}

Since the creation of the first business incubation mechanism in the late 1950s, substantial academic and industry attention has been devoted to this topic, with the range of research orientations and business models that have emerged (Hackett and Dilts 2004) mainly featuring 'technology/business incubators, innovation/technology centers, science/research/technology parks, and business/seed accelerators' (Mian et al. 2016, p. 2). Despite these variations, incubation models have generally had the objective of supporting innovative start-ups, corporate employees or academic spin-offs during the entrepreneurial process (Pauwels et al. 2016; Mian et al. 
2016). That said, the models that have so far gained the most attention are business incubators and accelerators (Mian et al. 2016). Thus, this section presents the definitions and distinctive characteristics of business incubators and accelerators.

Business incubators are organisations that promote the creation and growth of innovative start-ups by providing business support services, access to resourceful networks and office working spaces (Bergek and Norrman 2008; Hackett and Dilts 2004). An incubator network typically comprises of incubator advisors, participating incubatees, regional universities and industry connections and may extend to include resource providers like lawyers, investors, accountants and consultants with industry and technological knowledge (Hackett and Dilts 2004). Peters et al. (2004) identify three main types of governance structures in business incubators: (1) nonprofit models affiliated with government agencies, (2) non-profit incubators affiliated with universities and (3) for-profit models linked to private organisations. The latter may demand up to $70 \%$ of equity in participating start-ups in exchange for their support. Given the established nature of research on incubation models, Hackett and Dilts (2004) present five research orientations: developmental studies contributing taxonomies and typologies, configuration studies defining how incubation models operate, incubatee-focused studies exploring tenants' experiences and perspectives, impact studies measuring the outcome of incubation models and theory-building studies. Due to a lack of research on incubation models in the FinTech context (Alaassar et al. 2021a) and our objective of reviewing the literature on innovation facilitators, we argue that our research is most closely aligned with the configuration and impact studies category. Thus, we briefly review how business incubators and accelerators function.

Bergek and Norrman (2008) assert that business incubators are composed of five key building blocks that are reflected in how they operate: (1) selection involves screening and acceptance or rejection of tenants based on entry requirements; (2) infrastructure refers to offering office spaces and administrative support; (3) business support services are related to developmental activities like coaching tenants; (4) mediation represents the act of connecting incubatees to external networks in order to access resources; and (5) graduation is associated with exit decisions and policies. Unlike business incubators, accelerators have only emerged in the past two decades and are commonly short-term, fixed-duration and cohort-based programs offering mentorship and co-working spaces for start-ups (Mian et al. 2016). Additionally, in comparison to incubators, Pauwels et al.'s (2016) recent exploration of accelerators indicates that they are more focused on offering access to investment opportunities, are industry or geography focused and may employ a selection process that involves using third-party services to conduct bulk screening.

While the literature indicates that incubation models tend to be dominant in most industries (Mian et al. 2016), this is not necessarily the case for the financial sector (Alaassar et al. 2021a). Here, other innovation facilitators have emerged to meet the distinctive features of this context: highly regulated with often outdated regulatory frameworks, newcomers with a lack of regulatory understanding and the potential to inflict harm on financial stability (Alaassar et al. 2021a). As such, the rise of regulator-led instruments like regulatory sandboxes and innovations hubs or labs is found to both promote and regulate financial innovation activities. Moreover, accelerator 
programs are found to be favourable and widely distributed incubation models, especially from the perspective of traditional financial institutions, which are able to effectively gain insight into novel technologies and solutions (Nicoletti 2017). These differences in incubation model orientations in the financial sector raise the question of which and how existing innovation facilitators operate in that context, a knowledge gap that is addressed in this review.

\section{Methods}

Using LR and content analysis, our approach involved searching, selecting, coding and creating categories (Belderbos et al. 2017; Tranfield et al. 2003). The NVivo software package was employed to facilitate this analysis (Adams et al. 2017; Gaur and Kumar 2017; O'Kane et al. 2021). The selected unit of analysis is the academic article. Figure 1 outlines the research methodology employed in this review.

\subsection{Search and selection}

Prior to searching for and selecting the sample, a pre-study of management studies exploring the topic of financial innovation and innovation facilitators in the FinTech era was conducted (Alaassar et al. 2020; Goo and Heo 2020; Mention 2020; Mention and Torkkeli 2012). This helped evaluate the scope of the existing literature, refine the review topic and identify relevant search strings. Thereafter, keywordbased and external-article search strategies were followed to ensure that all relevant papers would be included in the sample. For the keyword-based search, we used

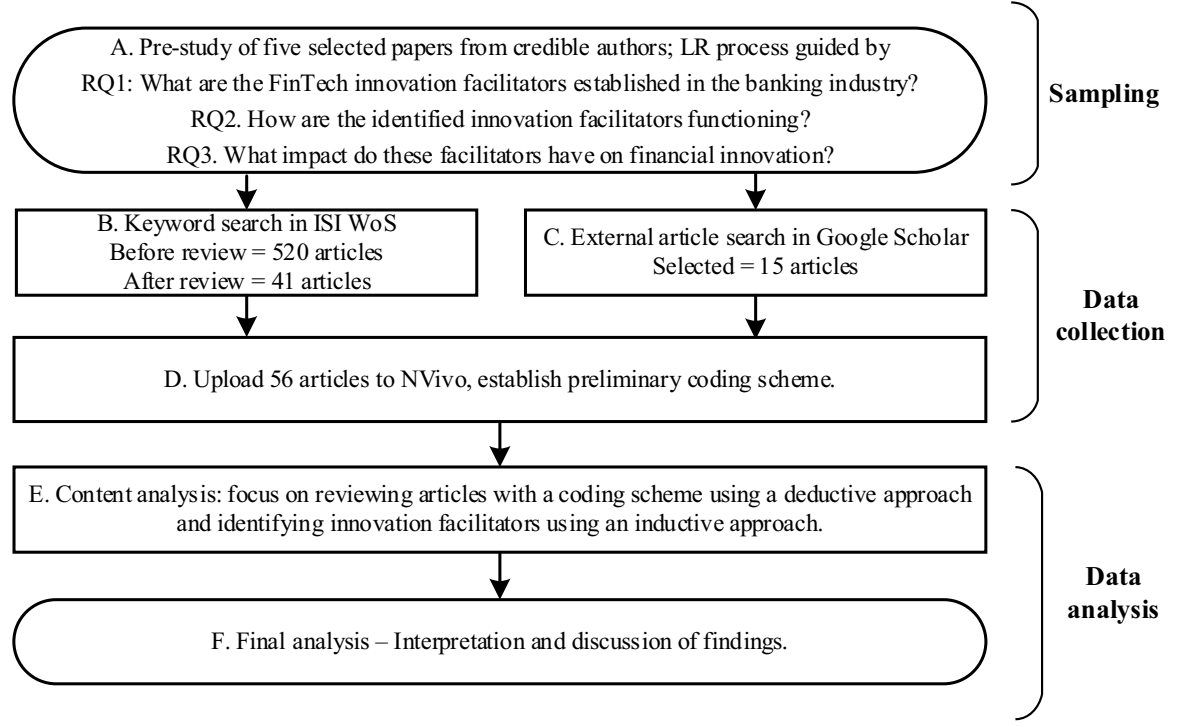

Fig. 1 LR process 
Table 1 Search strings and selection

\begin{tabular}{|c|c|c|c|}
\hline \# & Search strings WoS & Search & Selection \\
\hline 1 & $\begin{array}{l}\text { (Incubat* OR accelerat* OR instru- } \\
\text { ment* OR mechanism* OR initia- } \\
\text { tiv* OR hub* OR framework* OR } \\
\text { facilitat*) AND 'financial innovat*' }\end{array}$ & $285^{\mathrm{a}}$ & 28 \\
\hline 2 & $\begin{array}{l}\text { (Incubat* OR accelerat* OR } \\
\text { instrument* OR mechanism* OR } \\
\text { initiativ* OR hub* OR framework* } \\
\text { OR facilitat*) AND (fintech OR } \\
\text { 'financial technology') }\end{array}$ & $235^{\mathrm{a}}$ & 16 \\
\hline Total & & 520 & 44 \\
\hline Total accessible ${ }^{\mathrm{b}}$ & & & 41 \\
\hline Additional contributions ${ }^{\mathrm{c}}$ & & & 15 \\
\hline Total number of papers for analysis & & & 56 \\
\hline
\end{tabular}

Duplicates were not counted, so the 'selected' number of articles may appear lower than expected

${ }^{\text {a}}$ Limited to article, review and early access document types

${ }^{\mathrm{b}}$ Some papers had limited access, while others were not written in English

${ }^{c}$ External papers from reputable authors sourced from Scopus and Google Scholar

the following strings in two separate searches: (1) ((incubat* OR accelerat* OR instrument* OR mechanism* OR initiativ* OR hub* OR framework* OR facilitat*) AND 'financial innovat*'); and (2) ((incubat* OR accelerat* OR instrument* OR mechanism* OR initiativ* OR hub* OR framework* OR facilitat*) AND (fintech OR 'financial technology')). This keyword search was conducted in the ISI Web of Science $^{2}$ (WoS) database in December 2020 and generated 520 articles after filtering to include only article, review and early access document types; no time period limits were applied. Following this, the titles, abstracts and keywords were reviewed to ensure relevance to the research scope, which led to the selection of 44 articles, of which only 41 were accessible and published in English. The majority of excluded publications were from the fields of economics, business finance and law and had little to no relevance to supporting businesses with their innovation efforts from a management studies perspective. In addition, we conducted an external search using Google Scholar, which resulted in selecting 15 relevant $^{3}$ contributions that were not identifiable on WoS; backward and forward citation tracking was utilised to identify additional relevant contributions. Thus, 56 papers were prepared for analysis (see "Appendix 2" for an overview). Table 1 presents the number of searches, the keyword strings and the number of selected articles.

The distribution of the journals was extremely diverse; Small Business Economics published the largest number of papers in our sample, but that was a mere four papers.

\footnotetext{
${ }^{2} \mathrm{WoS}$ was deliberately selected as a top-ranked database to limit lower-quality publications.

${ }^{3}$ These include articles from key outlets targeting this topic but published in different formats like working papers (e.g., Cornelli et al. 2020) and books (e.g., Fenwick et al. 2020).
} 
It is also notable that the number of papers published in law journals was almost equal to the number in management journals. The remaining studies stemmed from other journals published in economic outlets. As for publication year, most studies (73\%) appeared between 2018 and 2021, which emphasises the intensive attention this topic has received in the past few years. Figure 2 illustrates the distribution of journals, and Table 2 outlines the most frequently cited articles in the analysed sample.

\subsection{Data analysis}

The next stage in the review process was to employ content analysis and both deductive and inductive approaches on the sample of 56 papers. NVivo was used to facilitate this process (Adams et al. 2017; Gaur and Kumar 2017; O'Kane et al. 2021). As a starting point, a pre-coding scheme was developed in line with the scope of this review. This included categories such as descriptive data (journal, title, author(s), research question(s), method(s), findings and results and suggestions for future research), innovation facilitators (definition and activity description) and implications (consequences and benefits). During the process of analysis, the pre-coding scheme was gradually modified with new inductively coded sub-categories capturing different innovation facilitators from the perspective of regulators, newcomers and incumbents. After all studies were reviewed, the coded data were compiled in a framework matrix consisting of the analysed studies on the vertical axis and the categories on the horizontal axis. This matrix began the data synthesis and write-up process presented in Sect. 4, which reports the results of the literature review.

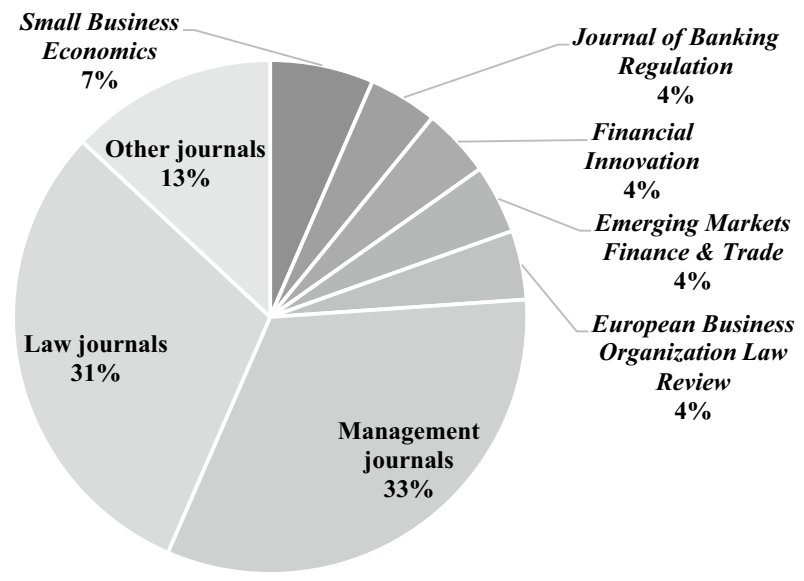

Fig. 2 Overview of journals in which articles in the sample articles appeared 


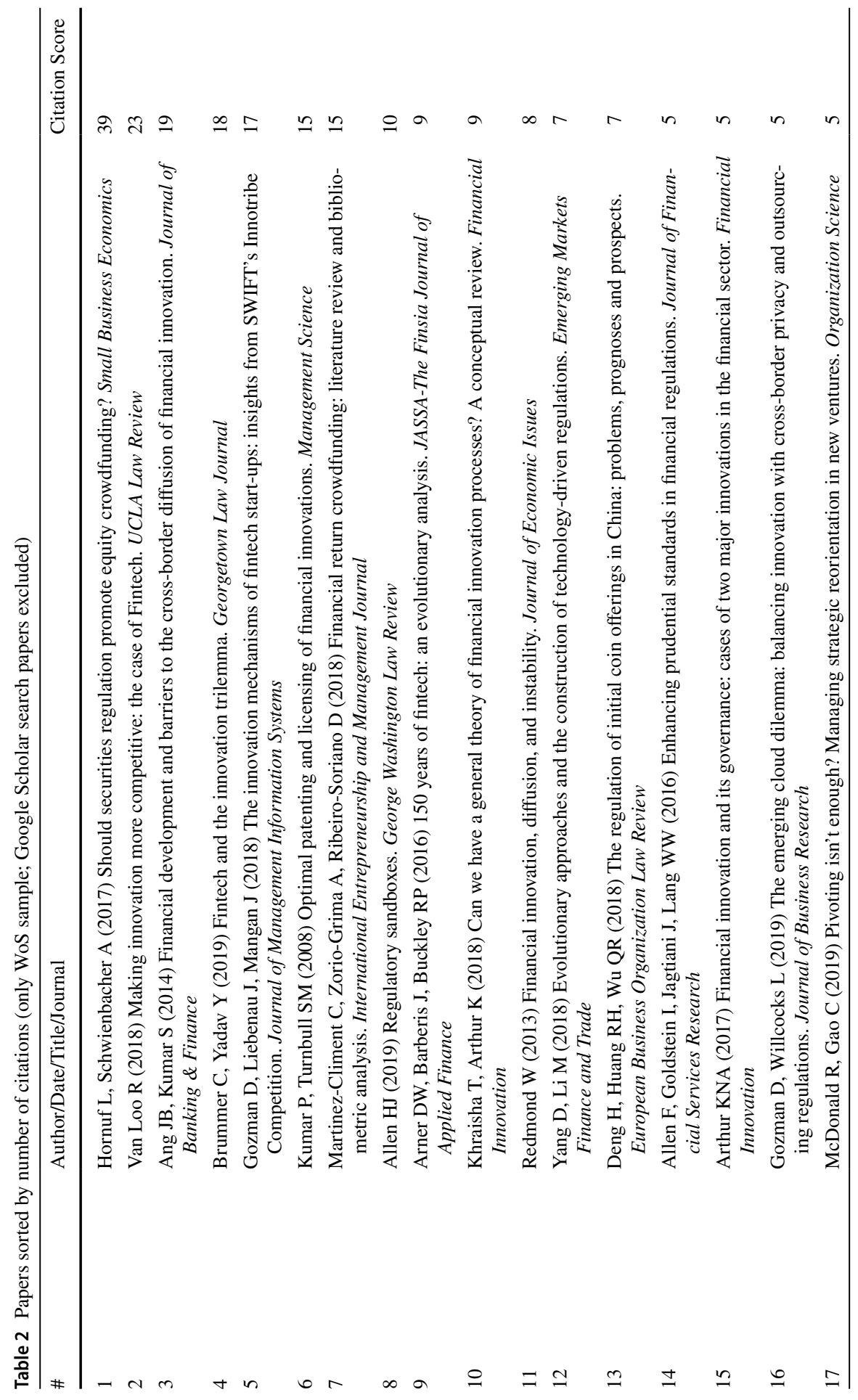




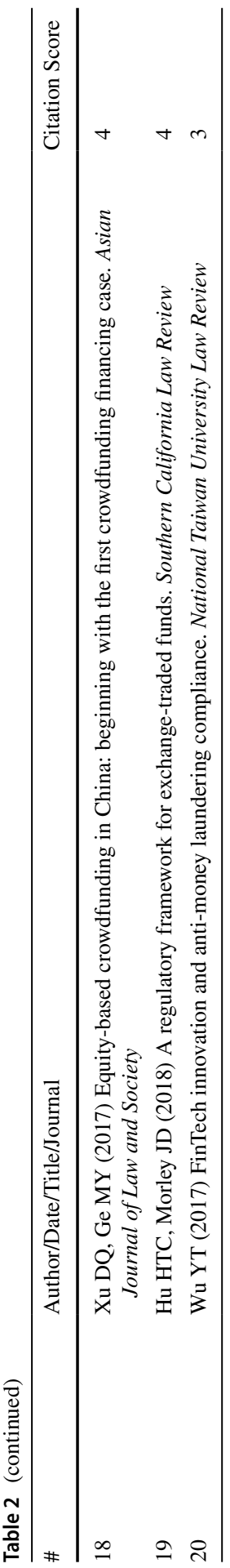




\section{Results}

This section presents the results of the content analysis of 56 papers focusing on FinTech innovation facilitators and related underlying processes and consequences. This analysis revealed three main categories of innovation facilitators in the literature from the perspective of regulators, incumbents and newcomers. With the exception of regulatory sandboxes (general unacceptance of cryptocurrency offerings) and ICOs (dedicated to blockchain and cryptocurrency segment), all other innovation facilitators had a broad scope to targeted FinTech segments. An overview of the findings and associated data structure can be found in Fig. 3. Table 4 in the appendix summarises the 10 most relevant papers that emerged from the analysis.

\subsection{Regulator-led innovation facilitators}

Regulator-led instruments primarily include regulatory sandboxes and thematic sandboxes, innovation hubs and incubation models.

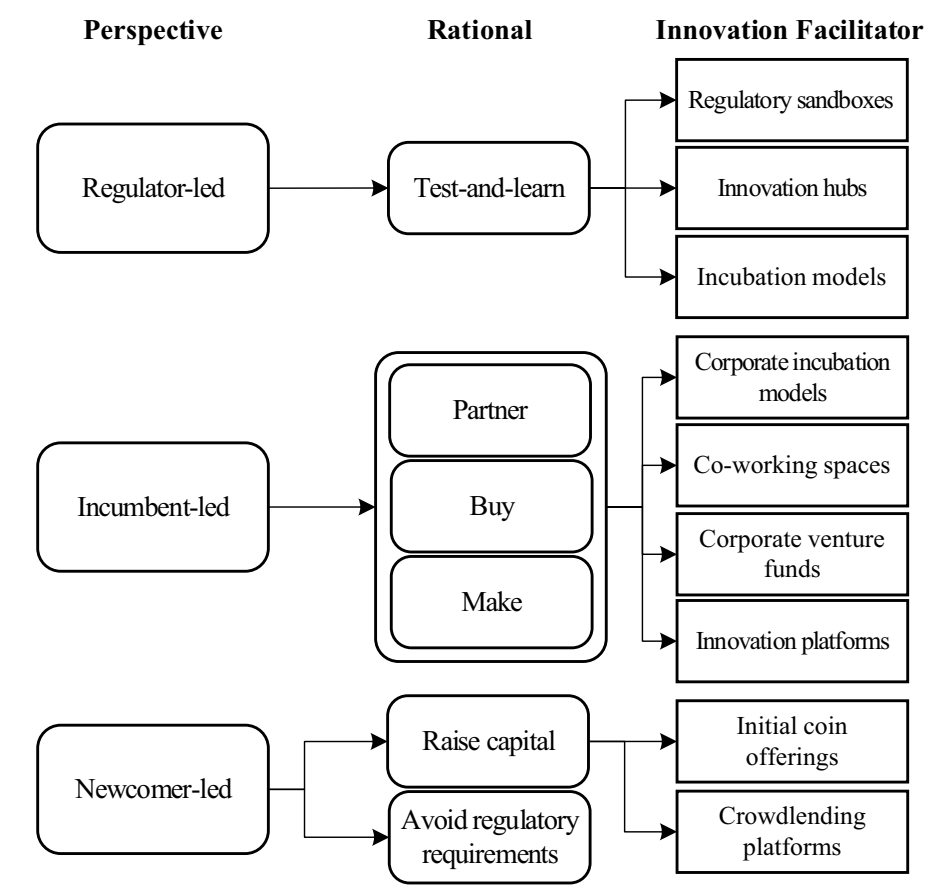

Fig. 3 Overview of the findings 


\subsubsection{Regulatory sandboxes}

The most frequently investigated innovation facilitator established by regulators is the regulatory sandbox. Pioneered by the Financial Conduct Authority (FCA) in the United Kingdom, the inspiration for sandboxes came from clinical trials in the pharmaceutical industry (Ahern 2020). First established in 2016, they are either already operating or have been announced in more than 50 jurisdictions (Buckley et al. 2020a). Irrespective of the fine details of deployment, sandboxes are virtual trial-and-error instruments that grant financial market participants temporary licensing relief, providing the opportunity to test novel solutions in a controlled, real-world environment and engage with regulators who offer guidance and supervision (Brummer and Yadav 2019; Fenwick et al. 2020). The sandbox approach means that risks - to consumers and investors, whether operational or systemic - may be contained and that regulators can learn about the application and implication of enabling technologies. Sandbox participants, meanwhile, benefit from access to regulatory knowledge, convenient testing in both local and international jurisdictions (facilitated through cross-border collaboration and initiatives like the Global Sandbox) and the freedom to operate and compete in financial markets dominated by traditional financial institutions (Alaassar et al. 2020; Allen 2019; Ringe and Ruof 2020). Ahern (2020) characterises sandboxes as an agile form of opportunity-based regulation, distinguishing them from the passive wait-and-see approach and risk-based regulation traditionally associated with financial regulators.

With regard to the processes inherent in sandboxes, our findings indicate the presence of application, participation and graduation or termination processes. Upon application, FinTech applicants must meet a set of eligibility criteria that are evaluated to enter the sandbox (e.g., degree of innovation, benefit for consumers, readiness and need for testing). For instance, readiness for testing is evaluated based on a detailed description of risk mitigation plans and success indicators to ensure the presence of necessary safeguards. If applicants meet the eligibility criteria, then regulators consider which legal frameworks are applicable to tailor testing conditions or relax regulatory requirements, such as waiving rules or issuing no-enforcement action letters for admitted applicants (Ahern 2020; Huang et al. 2020). Importantly, existing literature (e.g., Alaassar et al. 2021a) indicate that regulators welcome most types of FinTech segments to apply to access the regulatory sandbox; the FCA sandbox in the United Kingdom with the highest number of sandbox participants in the world, has accepted applicants operating in all segments including cryptocurrencies. However, many other regulatory jurisdictions have a ban on blockchain and cryptocurrency offerings (Buckley et al. 2020a). During participation, we find empirical evidence of regulator-regulatee social interaction contributing to the practices of both regulators and sandbox participants in ways such as improving risk management and regulatory compliance practices among participants and enhancing regulators' monitoring and engagement practices (Alaassar et al. 2020). Finally, participants must exit the sandbox either upon completing testing plans, reaching the scheduled end of the participation period or being terminated due to non-compliance with regulatory requirements (Ringe and Ruof 2020). 
While empirical studies investigating the implications of sandboxes remain scarce, our findings provide novel insights that contribute to the scholarly understanding of sandboxes. For instance, anecdotal evidence indicates that sandboxes provide participants with credibility and a stamp of approval (e.g., Ahern 2020; Allen 2019). This concurs with the empirical findings of Alaassar et al. (2020), who found that sandbox participants are indeed perceived as trustworthy by investors and consumers, thus gaining legitimacy and wider acceptance. Consequently, it is further postulated that sandboxes facilitate access to finance (Alaassar et al. 2020). Using a sample of 118 participants, Cornelli et al. (2020) found a significant increase in capital raised after sandbox entry, confirming the effectiveness of sandboxes at improving FinTech participants' access to investment capital. From a country-level perspective, Goo and Heo (2020) also found a positive effect of sandboxes on FinTech venture investments. Moreover, the literature discusses the signalling effect that sandboxes achieve, which reflects the commitment of regulatory authorities to promote innovation (Allen 2019; Buckley et al. 2020a). It is, however, questionable whether sandboxes can inform us with sufficient certainty about the implications of the wide-scale deployment of FinTech. This is because sandboxes impose testing conditions with limited thresholds; for instance, the Australian Securities and Investments Commission's (ASIC) sandbox limits testing participants to 100 retail clients. Even if a robo-advisory FinTech (an automated, algorithm-driven financial portfolio advisor) is successful in small-scale testing, the extent to which this service might effectively work with a larger group of more diverse clients could be very different (Brummer and Yadav 2019). Brown and Piroska (2021) claim that sandboxes are engaged in riskwashing, a term used to describe organisations' actions to appear as if they are de-risking an asset class, technology or business model. The riskwashing effect of sandboxes is justified through three characteristics: the first point concurs with Brummer and Yadav's (2019) view on the inability of small-scale tests to generate adequate knowledge about the actual systemic effects on society and the economy that are attributable to newcomer FinTechs. Second, there is a degree of opacity in the design of sandboxes; risk-related information shared with consumers and external stakeholders based on the dialogue among regulators and sandbox participants is opaque and selective. Third, since sandbox regulators are involved in the co-creation of participants' services and business models, the authors claim that FinTech participants may lack the capabilities to independently evaluate and develop their risk profiles after graduating from the sandbox (Brown and Piroska 2021).

Lastly, we present evidence of sandbox models evolving into thematic testing environments. For instance, in Hong Kong, the regulatory authorities have introduced a two-stage sandbox to enhance existing regulations for cryptocurrency platforms. The first stage is exploratory, a trial period during which participants engage in live testing to illustrate how regulatory requirements will be met. Once regulators are satisfied with the regulatory effectiveness of a participant's operations, the applicant is granted a time-limited license of at least 12 months to start the second stage, though close monitoring continues (Huang et al. 2020). Similarly, sandboxes have been proposed as appropriate testing labs for RegTech, which uses Big Data and machine learning to provide real-time data on irregularities. Thus, RegTech can facilitate effective monitoring and regulation of a large number of market 
participants (Arner et al. 2016; Yang and Li 2018). In the EU context, Buckley et al. (2020b) argue that the combined effect of four legislative measures have been conducive to the evolution of RegTech: digital regulatory reporting requirements (AIFMD and MiFID II), data protection (GDPR), open banking (PSD 2) and digital identification (eIDAS).

\subsubsection{Innovation hubs}

Another innovation facilitator identified in the literature was innovation hubs, ${ }^{4}$ which are primarily intended to be easy-to-access engagement points for financial market participants to receive clarification and guidance on applicable financial regulations (Ahern 2020; Buckley et al. 2020a; Khalid and Kunhibava 2020), such as questions about whether and how regulatory frameworks apply with regard to anti-money laundering efforts and ICOs (Ahern 2020). Some jurisdictions offer both innovation hubs and regulatory sandboxes as part of their contribution to supporting technology-enabled innovation in financial markets (Brummer and Yadav 2019). However, innovation hubs are often the first initiative employed by regulators (Khalid and Kunhibava 2020). In the EU, five countries had established sandboxes by 2019, while 24 EU countries had set up innovation hubs (Laidroo and Avarmaa 2019).

Buckley et al. (2020a) focus on the differences between sandboxes and innovation hubs, arguing that innovation hubs have more benefits in supporting FinTech ecosystems; they are less resource intensive, are open to a wider range of FinTech firms and can operate as stand-alone initiatives. The only drawback of innovation hubs these authors found was that they are not recognised as a unique brand and are used interchangeably with other initiatives like accelerators; in this regard, they differ from regulatory sandboxes. Both innovation hubs and sandboxes enable mutual knowledge exchange among regulators and innovators (Ahern 2020; Buckley et al. 2020a) and facilitate referrals to international jurisdictions, provided that there are bilateral agreements with a referral function between a given country pair (Ivanova 2019).

\subsubsection{Incubation models}

Incubation models such as business incubators and accelerators resemble the last initiative identified in the analysed literature by serving as innovation facilitators. These instruments provide a variety of opportunities for business support, collaboration, experimentation and co-working spaces (Ahern 2020). Although regulatory authorities in countries like Germany, Luxembourg and the United States (at the federal level) may not have introduced sandboxes to promote FinTech innovation activities, they have adopted other approaches that are dominated by incubation models

\footnotetext{
${ }^{4}$ Note that these initiatives are established and governed by regulatory authorities and are thus distinct from government-supported, community-led and private innovation hubs. The incubation models presented in the next subsections differ in that they can be publicly funded.
} 
(Buckley et al. 2020a). In these settings, incubation models are partly or entirely established or funded by public agencies rather than banks (Hornuf et al. 2020). For example, the Bank of England established an accelerator to support the implementation of financial innovation in the United Kingdom's central banking system by running exploratory proof of concept (PoC) on business cases of relevance. Although the central bank doesn't specify which FinTech areas are of relevance, they have completed PoCs with segments like RegTech (auditing), blockchain and cryptocurrencies (privacy related) and money transfer, thus indicating wide acceptance (Laidroo and Avarmaa 2019). Using a large dataset of FinTech start-ups established in France, Gazel and Schwienbacher (2020) confirm that incubation models significantly lower the risk of failure for their FinTech tenants. That said, there remains scant research investigating the functions and implications of incubation models for FinTech innovators.

\subsection{Incumbent-led innovation facilitators}

The literature indicates the role of traditional banking institutions and technology firms as innovation facilitators using corporate strategies that contribute to the creation and growth of FinTech innovations. In this setting, Nicoletti (2017) presents three main strategies that traditional financial institutions adopt to maintain their competitive advantage in the digital transformation of financial services: partnering, purchasing and making.

\subsubsection{Partner, buy or make strategies}

Broadly, the partner, buy or make strategies focus on FinTech categories within digital payments and banking, lending and wealth management (Tanda and Schena 2019). Partnering features combining incumbents' in-house capabilities with the agility of start-ups to develop new business models. Though the literature capturing this perspective remains scanty, Hornuf et al. (2020) do discuss the role of incumbents and their collaboration with FinTech start-ups. Using data from the largest banks in four regulatory jurisdictions, the authors found that incumbents are more likely to invest in smaller FinTech entities and establish product-related alliances with larger ones. The majority of these collaborations were attributed to FinTechs operating in the digital payments segment across the four countries. Distinctively, a high number of FinTechs providing bank-level software like customer relationship management tools (United Kingdom) and asset management solutions (Germany) were reported (Hornuf et al. 2020). Relatedly, Klus et al. (2019) explore both incumbent and FinTech perspectives, identifying different motives for partnering; traditional financial institutions seek FinTech start-ups mainly to outsource exclusive services, whereas start-ups pursue incumbents' regulatory capabilities, reputation and customer base. As such, the authors argue that banks could be exposed to reputational loss in the case of malpractice from partner FinTechs (Klus et al. 2019).

In any case, the operationalisation of each strategy can be achieved through different innovation facilitators like launching venture capital funds (e.g., AXA's $€ 200$ 
million fund in 2015), setting up incubators or accelerators (e.g., Barclay's New York accelerator) or establishing co-working spaces (e.g., Level39 in London) that are further leased by financial institutions to new entrants (Hendrikse et al. 2018; Nicoletti 2017). When unpacking support programs like Barclay's New York accelerator, it is reported that eight investment contracts were signed upon the completion of the 2015 program with FinTechs in areas like cloud computing, cybersecurity, digital signatures, remote conferencing and loan information (Nicoletti 2017). Sinha (2017) provides an example of the role of the Open Vault accelerator at Singapore's OCBC Bank; if a start-up is able to validate its solution and market fit, then OCBC becomes its first customer, thus achieving first-mover advantage along with increases in customer base and revenue (Sinha 2017). OCBC Bank is particularly interested in FinTechs using technologies like (1) data analytics to process vast amount of data and help tailor services to customers, (2) artificial intelligence to automate services like lending enabled chat bots that provide information to existing and potential customers interested in loans and (3) blockchain to facilitate 'Know your customer' processes (Sinha 2017).

In addition to the adoption of individual instruments, Hendrikse et al. (2018) report the presence of co-located joint venture clusters formed by two or more traditional financial institutions as a collaborative effort to explore common opportunities arising from new FinTech entrants. As an example, B-Hive-a European collaborative innovation platform for FinTech-brings together major financial institutions to provide access to incubators, networking events and support initiatives. As such, traditional financial institutions play the role of platform leaders in FinTech entrepreneurial ecosystems. Notably, some of these incumbent-led initiatives are thematic (e.g., focusing on the application of certain technologies like blockchain), spatially global (e.g., the Global FinTech Hubs Federation as a cross-border innovation network) and temporal (i.e., project-based) in nature. Nonetheless, in all the approaches that traditional financial institutions employ, they have the objective of cultivating relations and gaining early access to and control of innovative financial solutions (Hendrikse et al. 2018).

Beyond the strategies described above that reflect state-of-the-art incumbent-led innovation facilitators, Fenwick and Vermeulen (2020) propose the adoption of other strategies that stem from innovative organisations like Apple, Google, Amazon and Netflix; they primarily operate as technology firms outside the financial sector but have more recently expanded their service offerings to include financial services. For example, Apple launched its first credit card in 2019, while Google debuted bank accounts and Facebook introduced Libra, a new digital currency (Hendershott et al. 2021). These strategies feature, first, the creation of an environment conducive for serendipity (i.e., coincidental engagements among corporate employees and entrepreneurial actors that lead to commercially value-adding outcomes). Although incubators and accelerators may be appropriate instruments to achieve this goal, it has been argued that co-working spaces with open office arrangements can more effectively foster positive incumbent-start-up interactions. Second, while the acquisition of innovative start-ups is widely practised, the authors point out the importance of maintaining the entrepreneurial firm's identity and culture instead of having it absorbed into the acquiring company. The last strategy, though focused on 
intrapreneurship, presents a model that combines in-house incubator and accelerator programs with the creation of corporate venture funds to cultivate an entrepreneurial culture within incumbents (Fenwick and Vermeulen 2020). In order to execute their own innovation projects, financial institutions would require competent labour to support their make strategies and transformation into more technology-enabled organisations, and this is a trend that is becoming more prevalent. For example, the venerable investment bank Goldman Sachs has more than 9000 in-house programming and engineering employees out of a total of 33,000 professionals (Hendershott et al. 2021).

\subsubsection{Open versus closed strategy to financial innovation}

Another categorisation that emerged from the LR involved arranging incumbent-led strategies across a spectrum (from closed to open) featuring the degree of incumbents' willingness to collaborate with FinTech start-ups. On one hand, it has been argued that digital transformations are easier to realise in closed corporate structures rather than open ones due to efficiency, data security, customer service and intellectual property issues. On the other, evidence indicates that open structures allow incumbents to significantly improve their offerings. The Spanish bank BBVA offers a good example through the launch of its open banking program, effectively making eight application programming interfaces commercially accessible to third-party FinTech start-ups, allowing them to incorporate customer's banking data into new solutions with enhanced user experience like identity verification, payment management and loan authorisation. That said, the majority of traditional financial institutions are still in the experimental stages of deploying an open corporate strategy (Hendrikse et al. 2018).

\subsection{FinTech-led innovation facilitators}

Our analysis of the literature also identified instruments developed and adopted by FinTech start-ups to overcome specific challenges, such as raising capital (e.g., ICOs and crowdlending platforms) and compliance with regulatory requirements; these are discussed below.

\subsubsection{ICOs and peer-to-peer platforms}

ICOs have evolved as the preferred tool to raise capital using cryptocurrencies. The first ICO token fundraising was conducted in 2013 by Mastercoin, now known as Omni (Deng et al. 2018), with interest gradually growing thereafter; US\$7.9 billion were raised through ICOs in 2018 (Dostov et al. 2019). Unlike initial public offerings, which trade shares of stock in established entities with track records under heavy regulation, ICOs have little to no registration or reporting requirements, are used by nascent blockchain FinTechs and do not grant equity to ICO buyers. Instead, investors exchange cryptocurrency tokens for pre-order application tokens for a solution yet to be developed by the 
blockchain entity seeking to raise capital (Brummer and Yadav 2019; Cumming et al. 2019).

Since blockchain technology and cryptocurrencies like bitcoin are decentralised and have no central administrator, most jurisdictions lack the regulatory frameworks needed to protect not only individual investors but also entire economies (Cumming et al. 2019). As such, novel FinTech segments like blockchain and cryptocurrency providers that lack regulatory recognition and acceptance from ecosystem actors tend to raise capital using ICOs, as recent studies have confirmed (e.g., Alaassar et al. 2021b). It has also been suggested that such institutional voids trigger first-comer entrepreneurs to establish non-existing support mechanisms (e.g., entrepreneurial hubs, networking initiatives) that are crucial for the creation and survival of disfavoured FinTech start-ups. However, using a sample of 40 ICO-related soft law statements-those that impose no obligations but only offer regulatory guidance-issued by 37 regulatory jurisdictions, Dostov et al. (2019) confirmed the innovation-regulation lag and found that regulators are mostly concerned about fraud rather than deterring money laundering and terrorism financing. Despite those concerns, Cumming et al. (2019) argue that blockchain is a promising approach to facilitate entrepreneurial financing of new ventures and that regulations should promote rather than discourage it. Another alternative funding mechanism that has gained popularity in the past decade is investment-based crowdfunding, which is also called peer-to-peer (P2P); this mechanism involves lending platforms that play an intermediary role in connecting lenders and borrowers (Bavoso 2020; Martinez-Climent et al. 2018).

\subsubsection{Regulatory arbitrage as a practice}

Finally, while not being an instrument but rather an approach that debatably viewed as unethical, we briefly discuss regulatory arbitrage, which the literature identifies as a practice employed by some start-ups. Regulatory arbitrage occurs when financial market participants deliberately change the form of a financial activity to cleverly bypass regulatory requirements without affecting the risks associated with that activity (Allen et al. 2016; Boyer and Kempf 2020). This is often a consequence of the innovation-regulation lag, in which market participants introduce innovations in areas with vague regulation, regulators respond with complex compliance requirements, and innovators introduce new financial innovations or mechanims to overcome the ostensibly tougher regulations (Allen et al. 2016; Allen 2019). For example, in the United Kingdom, it is difficult to determine whether cryptocurrencies are subject to regulation and, if so, the regulated activity under which they fall. This lack of clarity in requirements provides innovators with the opportunity for regulatory arbitrage (Huang et al. 2020). Such practices have also been empirically identified in the FinTech context of Singapore (Alaassar et al. 2021b). 


\section{Discussion and conclusion}

This review has provided a synthesis of 56 studies on the literature discussing innovation facilitators in the FinTech era. Three main categories of initiatives were identified: those adopted by regulators, those adopted by traditional financial institutions and those adopted by newcomers. Each category initiative was defined and its processes and consequences reviewed. Our findings identified the regulatory sandbox as the most dominant innovation facilitator studied in the literature from the perspective of regulators. As for incumbents, accelerators and co-working spaces emerged as popular instruments. Finally, newcomers had also developed ways to tackle the hurdles in financial markets by raising capital through ICOs and P2P platforms. That said, there remain ample opportunities for future research due to the limited number of existing studies, most of which are conceptual in nature.

\subsection{A research agenda}

In addition to reviewing the literature on FinTech-related innovation facilitators, we synthesise the results and discuss several important observations from which suggestions for a future research agenda are derived. Table 3 provides a snapshot of the research questions derived from the discussion to support future scholarship.

Table 3 Research agenda for future scholarship on FinTech innovation facilitators

\begin{tabular}{ll}
\hline Thematic perspective & Suggested research questions \\
\hline Regulators & How effective are regulatory sandboxes in comparison to innovation hubs with \\
& regard to supporting FinTech innovation activities (factors to consider include \\
stakeholder engagement, time, governance, resources, activities and value \\
outcomes)? \\
What influence do regulatory sandboxes have on the reputation and contextual \\
attractiveness of leading FinTech jurisdictions? \\
What are the incentives for collaboration between incumbents and start-ups? \\
How are these incentives impacted by the presence of alternative innovation \\
facilitators? \\
How are incumbent-led innovation facilitators influencing the creation and devel- \\
opment of FinTech activities? \\
How do the competition dynamics among incumbents and start-ups with regard \\
to underlying antecedents, activities and implications affect FinTech innova- \\
tion? \\
How and why do technology firms interact with newcomers, incumbents and \\
regulators? \\
How do existing regulations facilitate or inhibit the presence and performance of \\
ICOs and P2P? \\
To what extent do regulated ICO and P2P campaigns affect investor protection \\
and newcomers' accessibility to capital? \\
How does the practice of regulatory arbitrage impact FinTech start-ups' ability to \\
raise funds from governmental grants, investors, ICOs or P2P campaigns? \\
Newcomers
\end{tabular}




\subsubsection{Synthesising regulator-led innovation facilitators}

The results on innovation facilitators that promote FinTech innovation activities can be placed on a spectrum. On one side, we have regulators that are still passive in their strategies to enable FinTech innovation activities. This side can be labelled 'risk-based regulation' and encompasses traditional activities like licensing. We also find other informal approaches adopted by regulators, such as public speeches or the issuance of no-enforcement action letters, which may signal an early change in regulators' strategies towards more active regulation. No-action letters can be issued to either a specific market participant or an entire sector to remove legal uncertainties associated with a given course of action (Brummer and Yadav 2019). On the other side of the spectrum, we observe more active regulation, with regulatory responses that deliberately foster test-and-learn activities for regulators and innovators. This side can be labelled 'opportunity-based regulation' and includes initiatives like regulatory sandboxes, innovation hubs and incubation models. Our review of the literature indicates that, since the 2008 financial crisis, most regulators in developed economies have transitioned from risk-based to opportunity-based outlooks on the innovation facilitators discussed above, although this shift may not include all FinTech segments, especially cryptocurrencies and ICOs. Figure 4 outlines the regulatory response spectrum.

While empirical evidence regarding the processes and consequences of innovation facilitators remains limited, there are studies confirming the positive impact of sandboxes on FinTech innovation actors, especially in terms of access to regulatory knowledge, cross-border referrals and enhanced investment opportunities (Alaassar et al. 2020; Cornelli et al. 2020; Goo and Heo 2020). Recent contributions (e.g., Buckley et al. 2020a) continue to emphasise the lack of data that are needed to gauge the effectiveness of sandboxes and argue that innovation hubs can more effectively support the FinTech ecosystem. These findings are interesting but raise the question of why regulatory authorities around the globe have invested large amounts of resources in creating more than 50 sandboxes, especially when our findings indicate that innovation hubs are often established prior to sandboxes; could this be solely due to reputational reasons and to signal the attractiveness of business conditions for

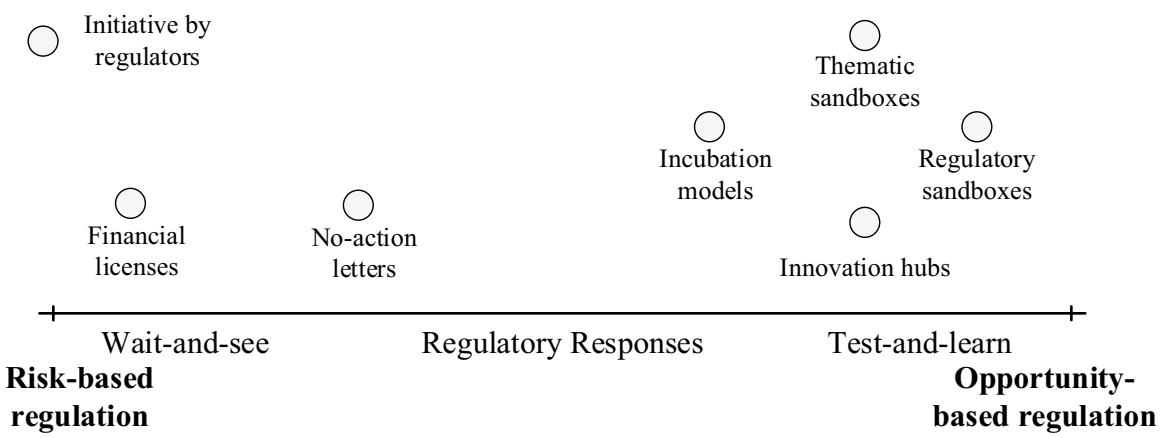

Fig. 4 The regulatory response spectrum (compiled by the authors) 
FinTechs? One may then ask whether there are inherent differences in the mechanisms and objectives of sandboxes and innovation hubs, with each tool serving a specific purpose. Future research is needed to investigate the building blocks and relationships among the stakeholders involved in these instruments as a first step prior to studies assessing their performance. Once achieved, comparative studies of regulatory sandboxes and innovation hubs can systematically investigate and report on the benefits and drawbacks of each instrument.

\subsubsection{Synthesising incumbent- and newcomer-led innovation facilitators}

We found evidence of incumbent-led innovation facilitators operationalised through partnering, buying and making strategies. This is where opportunities for future research in management studies are greatest, given that the majority of FinTech market participants offer business-to-business solutions, which often makes their business models depend on partnerships with traditional financial institutions. Scholars can build on the efforts of Hornuf et al. (2020) and Klus et al. (2019) to measure mechanisms like incentivising and economic growth after entering partnerships with incumbents. Additionally, in connection to partnering strategies, incumbents' use of innovation facilitators like co-working spaces were mainly discussed in the reviewed sample as spaces fostering serendipity that in turn leads to knowledge exchange and value creation (Fenwick and Vermeulen 2020). Although interesting, these findings barely scratch the surface of this phenomenon, hence future scholarship can benefit from the growing body of empirical research (e.g., Bouncken et al. 2020a, b) to guide exploration of incumbent-led co-working spaces in financial markets. It may also be hypothesised that the need for collaboration among ecosystem actorsbanks, start-ups, regulators, investors, support organisations and so on-is particularly high in the financial sector to access shared resources and knowledge. As such, the application of entrepreneurial ecosystems research can provide fruitful contributions to theory and practice by exploring how ecosystem actor interactions influence FinTech innovation activities (Bouncken and Kraus 2021; Alaassar et al. 2021b). Competition among business-to-consumer FinTech start-ups and banks is another promising topic that has not gained significant attention (Berman et al. 2021). In addition to collaboration and competition, future scholarship can investigate the coopetitive relationship between incumbents and start-ups (Hora et al. 2018) and the influence of coopetition on the creation and appropriation of value in corporate coworking spaces (Bouncken et al. 2018).

As with regulator-led approaches, our review of incumbent-led strategies can be presented on a spectrum extending Hendrikse et al. (2018) conceptualisation, spanning from 'closed' to 'open' strategies that represent the degree of incumbents' openness to FinTech collaboration. The partnering strategies on the open side of the spectrum dominate existing research, with little to no focus on the make and buy approaches, on the other side. Figure 5 outlines incumbents' response to FinTech penetration. Beyond bank-led approaches, our review has notably not come across studies that explore incumbent technology firms' strategies to collaborate with FinTech start-ups in the financial sector. Thus, future scholarship could investigate 


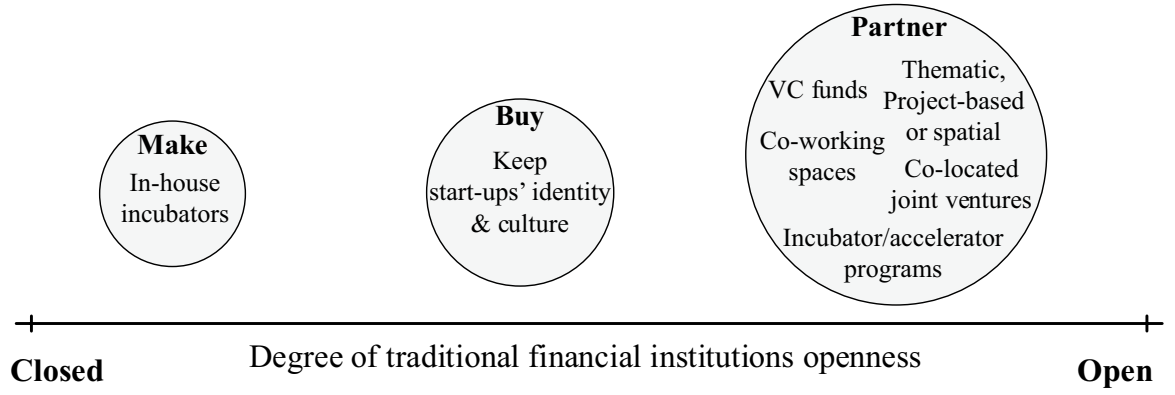

Fig. 5 Financial institution responses to FinTech penetration (compiled by the authors)

the innovation strategies that giant technology firms like Google and Apple have employed: have such firms mainly been focused on the closed end of the incumbent spectrum with make strategies involving in-house incubators? If so, as indicated in the existing literature (e.g., Hughes et al. 2018; Kraus et al. 2019; Covin et al. 2020), individual-level research on intrapreneurial employees remains rare and would thus be another interesting avenue for future scholarship for both incumbents and technology firms: how are the combined perspectives of individual- and organisationallevel factors and strategies influencing the generation and development of FinTech innovations?

Lastly, while our findings indicate the positive effect of sandboxes on FinTech start-ups' ability to raise capital, we also found evidence of other innovator-led approaches that enhance access to finance; namely, ICOs and P2P platforms, both of which have proved effective according to the literature. Though existing regulatory conditions for ICOs remain underdeveloped, thus limiting their potential in many jurisdictions, this situation is rapidly evolving as new regulatory frameworks are unveiled. Thus, future research should investigate the extent to which regulated ICO token sale campaigns may enhance investor protection measures and whether this would improve newcomers' access to capital and reduce the need for spatial proximity to attractive FinTech ecosystems. Another approach adopted by innovators was regulatory arbitrage, which allowed them to avoid regulatory requirements by taking advantage of unclear financial regulations. Though regulatory arbitrage has previously been debated in the broader financial market context, future research could seek to uncover the societal and economic implications of regulatory arbitrage among FinTech actors. How such a pragmatic approach to compliance influences FinTech start-ups' relationships with consumers and ability to raise funds are topics that have yet to be investigated in appropriate depth.

\subsection{Relevance of FinTech innovation facilitators to other industries}

This section is devoted to discuss the relevance of identified innovation facilitators beyond financial markets. Incubation model orientations including public and private support organisations have been widely adopted instruments across industries to support innovation and entrepreneurial creation and growth (Mian et al. 2016). 
More recent instruments like crowdfunding platforms and ICOs have also become popular fund raising instruments among innovators in different sectors (Fisch 2019; Klein et al. 2019; Block et al. 2018). Comparatively, regulator-led sandboxes have been distinct from previous support instruments given (1) the uncommon intervention of regulatory authorities in supporting innovation, (2) time-bound licensing exemptions, (3) ongoing engagement upon acceptance in which regulators offer guidance on regulatory frameworks, and (4) increased flexibility for FinTechs to operate and potentially compete with traditional financial institutions (Alaassar et al. 2021a). While innovation hubs and incubation models have also been established by regulators, they lack the unique features of sandboxes like providing time-limited licensing waivers and dedicated regulatory engagement, both of which if non-existent would incur high compliance costs. Despite the short history of regulatory sandboxes in financial markets, there is presence of spillovers to other sectors including the healthcare (Hirano et al. 2020; Leckenby et al. 2021) and energy sector (Veseli et al. 2021). As an example from the healthcare sector in Japan, Hirano et al. (2020) develop a data management system based on blockchain technology that was then tested in a clinical trial for breast cancer within the Japanese regulatory sandbox, which has been extended not only to cover financial markets and the healthcare industry, but also to mobility and transportation. As such, these findings indicate the need for regulatory intervention and the potential of innovation facilitators like regulatory sandbox to support innovative efforts across highly regulated sectors.

\subsection{Theoretical and practical implications}

Through this study, we have contributed, first, to incubation research by showcasing which industry-specific instruments have been either established or adapted by regulators, incumbents and new entrants (Alaassar et al. 2021a), and, second, to the financial innovation and FinTech literature streams by unifying existing contributions and mapping the contemporary state of knowledge on the activities and implications associated with innovation facilitators in the banking industry (Gazel and Schwienbacher 2020). Additionally, the findings derived contribute to debates on the role of new players in the entrepreneurial finance literature stream by confirming the positive impact of regulatory sandboxes on raising capital (Block et al. 2018).

This study also provides important practical implications to start-ups, regulators and incumbents. First, technology-enabled start-ups operating in regulated industries can benefit from the presented results by becoming cognizant of the existing development opportunities that each innovation facilitator can provide and accordingly use this information to develop strategies for new venture development, emergence and sustainability. As an example, innovators that lack financial licenses, have limited resources, access to legal help and knowledge about regulatory frameworks, and ones that will compete with traditional institutions, would benefit from regulator-led instruments like regulatory sandboxes and innovation hubs. Moreover, start-ups offering business-to-business services looking for ways to access and leverage regulatory capabilities including financial licenses, access to customer base and established reputation, will find the insights on incumbent-led innovation facilitators 
value-adding. In addition to incubation models, other instruments like innovation platforms, thematic initiatives and open banking programs offer numerous collaboration opportunities. ICOs and crowdlending platforms are also addressed in this review as alternative fundraising instruments, with the former being of particular interest to blockchain and cryptocurrency offerings that are often banned by regulatory authorities. Second, despite the wide-spread of regulator-led innovation facilitators in financial markets around the world, there remains great potential for regulatory change and intervention, especially in emerging economies. As such, the presented results provide an overview of relevant instruments and associated characteristics that can be transferred to other jurisdictions and regulated sectors. Last, the results are relevant for incumbents operating in and beyond financial markets as they showcase how different innovation facilitators can be employed depending on the desired partner, buy or make strategies as well as the degree of openness to collaborate for innovation.

\section{Research limitations}

There are no studies without limitations; we point out several methodological limitations related to the sampling approach which could be addressed in future research. First, the employed search strings could still have been broadened to capture more relevant studies. As an example, mechanisms like co-working spaces may have not been adequately identified due to missing keywords. Also, considering the wide application of enabling technologies in financial markets, the use of FinTech and financial innovation, may not always yield results on thematic applications including RegTech, crowdfunding, blockchain and cryptocurrencies. Second, despite using Scopus and Google Scholar to identify relevant contributions, WoS was the main database utilised. As this could be a limiting factor for the sample size, further research may consider using additional databases and grey literature more actively to capture impactful studies, without compromising the selection quality criteria. Third, citation tracking was performed on a smaller portion of selected contributions, thus future research can consistently use backward and forward citation tracking to identify contributions.

\section{Appendix 1: Summary of relevant articles}

See Table 4. 


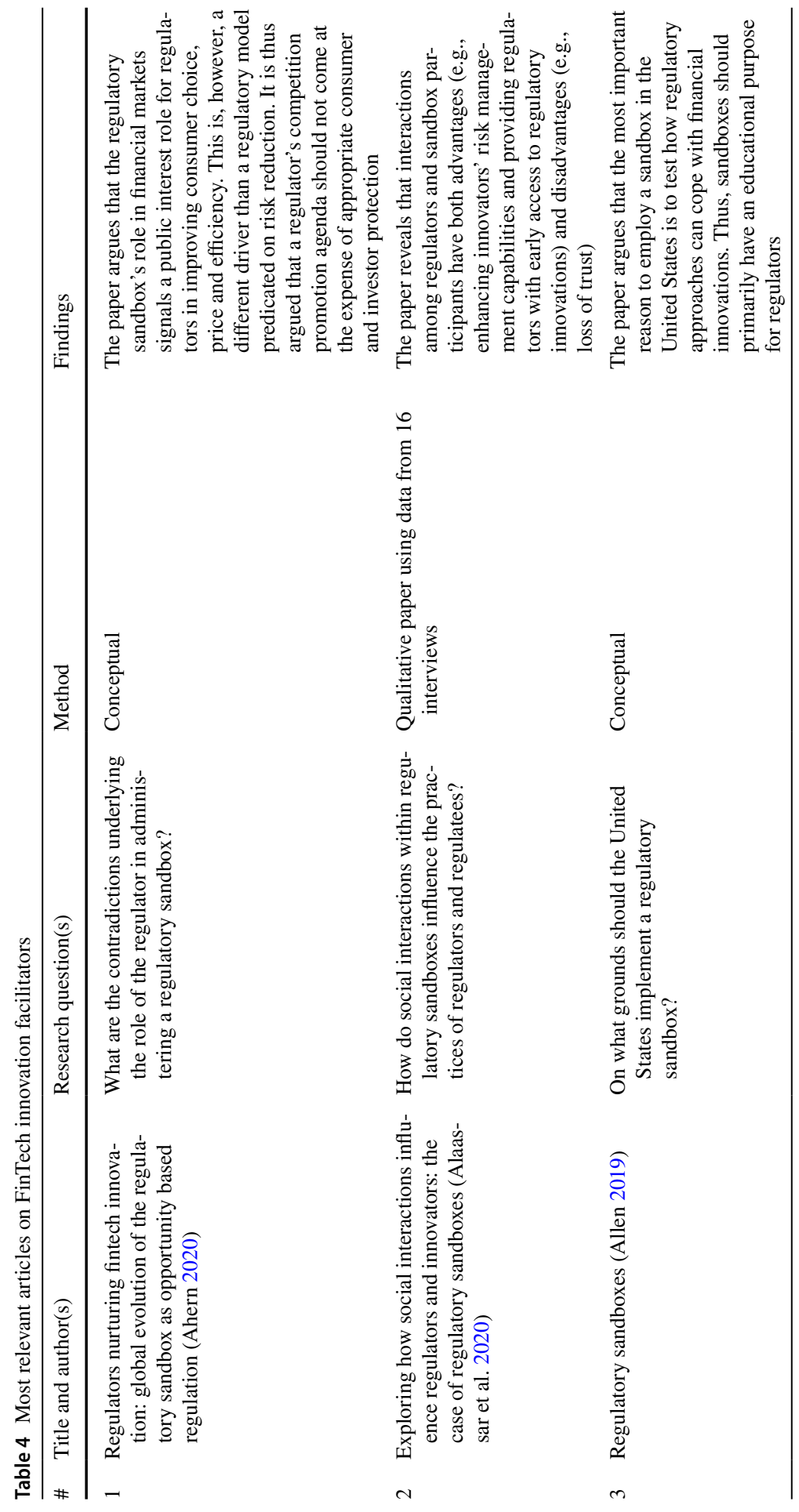




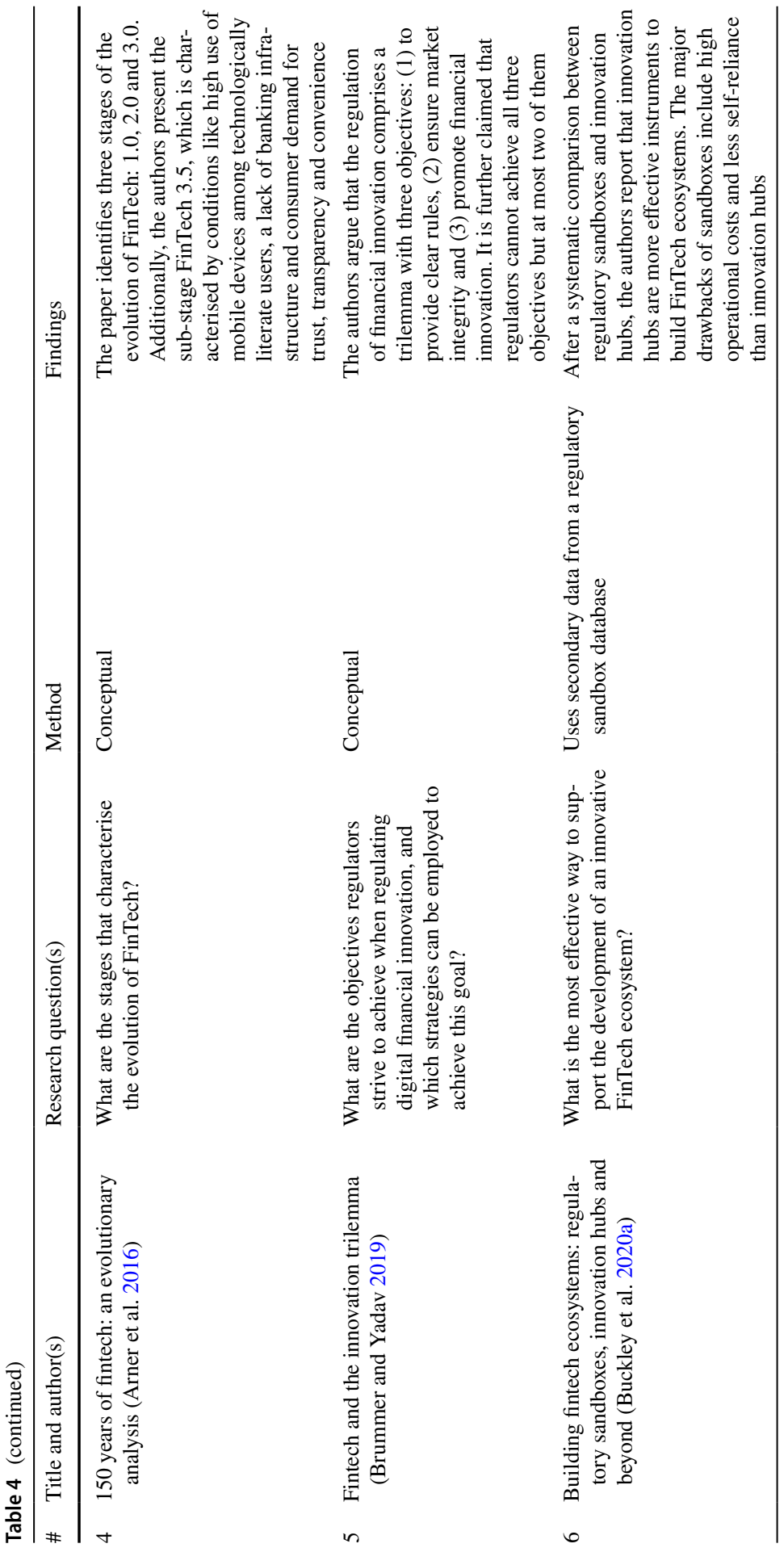




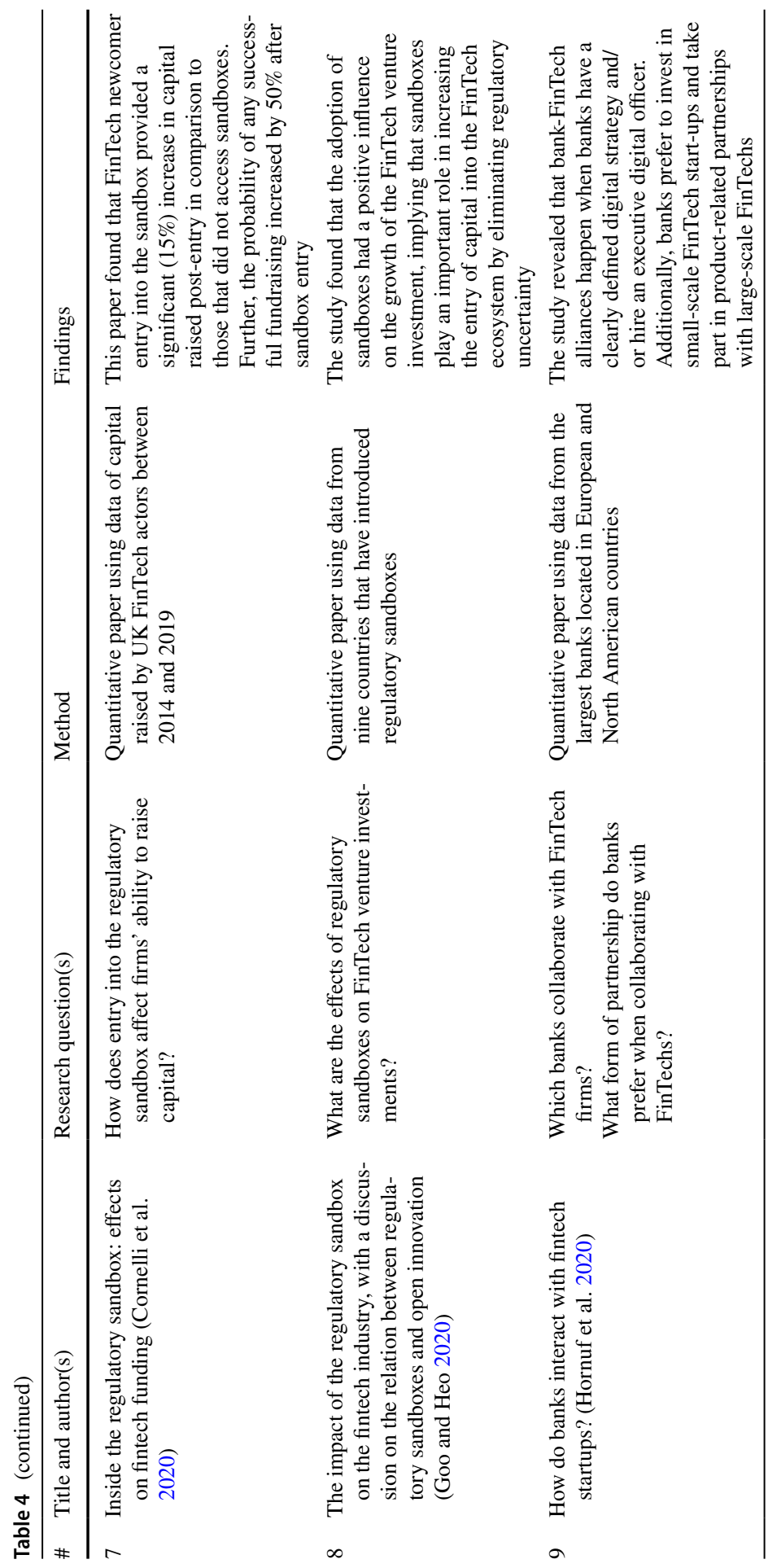




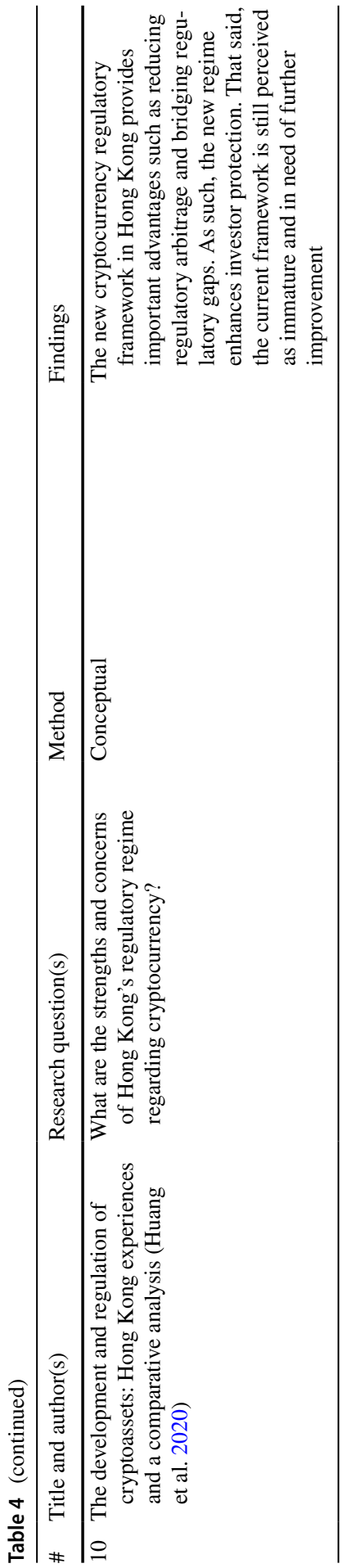




\section{Appendix 2: List of reviewed papers}

\# $\quad$ Author/Date/Title/Outlet (\#1-41 from WoS; \#42-56 first sourced from Google Scholar)

1 Alaassar A, Mention AL, Aas, TH (2020) Exploring how social interactions influence regulators and innovators: The case of regulatory sandboxes. Technological Forecasting and Social Change

2 Allen F, Goldstein I, Jagtiani J, Lang WW (2016) Enhancing prudential standards in financial regulations. Journal of Financial Services Research

3 Allen HJ (2019) Regulatory sandboxes. George Washington Law Review

4 Ang JB, Kumar S (2014) Financial development and barriers to the cross-border diffusion of financial innovation. Journal of Banking \& Finance

5 Arner DW, Barberis J, Buckley RP (2016) 150 Years of Fintech: an evolutionary analysis. JASSA The Finsia Journal of Applied Finance

6 Arthur KNA (2017) Financial innovation and its governance: cases of two major innovations in the financial sector. Financial Innovation

7 Bavoso V (2020) The promise and perils of alternative market-based finance: the case of P2P lending in the UK. Journal of Banking Regulation

8 Brummer C, Yadav Y (2019) Fintech and the innovation trilemma. Georgetown Law Journal

9 Buckley RP, Arner D, Veidt R, Zetzsche D (2020a) Building fintech ecosystems: regulatory sandboxes, innovation hubs and beyond. Washington University Journal of Law \& Policy

10 Buckley RP, Arner D, Zetzsche DA, Weber, RH (2020b) The road to RegTech: the (astonishing) example of the European Union. Journal of Banking Regulation

11 Chiu, IHY (2017) A rational regulatory strategy for governing financial innovation. European Journal of Risk Regulation

12 Cumming DJ, Johan S, Pant A (2019) Regulation of the crypto-economy: managing risks, challenges, and regulatory uncertainty. Journal of Risk and Financial Management

13 Deng H, Huang RH, Wu QR (2018) The regulation of initial coin offerings in China: problems, prognoses and prospects. European Business Organization Law Review

14 Dostov V, Shust P, Leonova A, Krivoruchko S (2019) "Soft law" and innovations: empirical analysis of ICO-related statements. Digital Policy Regulation and Governance

15 Gasiorkiewicz L, Monkiewicz J, Monkiewicz M (2020) Technology-driven innovations in financial services: the rise of alternative finance. Foundations of Management

16 Gazel M, Schwienbacher, A (2020) Entrepreneurial fintech clusters. Small Business Economics

17 Gianiodis PT, Thurer M (2018) The impact of government intervention on technological regimes: the sourcing of financial innovation. International Journal of Innovation Management

18 Gozman D, Liebenau J, Mangan J (2018) The innovation mechanisms of fintech start-ups: insights from swift's innotribe competition. Journal of Management Information Systems

19 Gozman D, Willcocks L (2019) The emerging cloud dilemma: Balancing innovation with crossborder privacy and outsourcing regulations. Journal of Business Research

20 Hornuf L, Klus MF, Lohwasser TS, Schwienbacher A (2020) How do banks interact with fintech startups? Small Business Economics

21 Hornuf L, Schwienbacher A (2017) Should securities regulation promote equity crowdfunding? Small Business Economics

22 Hu HTC, Morley JD (2018) A regulatory framework for exchange-traded funds. Southern California Law Review

23 Huang RH, Yang DM, Loo, FFY (2020) The development and regulation of cryptoassets: Hong Kong experiences and a comparative analysis. European Business Organization Law Review

24 Ivanova P. (2019) Cross-border regulation and fintech: are transnational cooperation agreements the right way to go? Uniform Law Review 
\# $\quad$ Author/Date/Title/Outlet (\#1-41 from WoS; \#42-56 first sourced from Google Scholar)

25 Jamil F, Ismail K, Mahmood N, Khan NU, Siddique M (2015) Technology incubators and institutional development. Jurnal Teknologi

26 Khalid M, Kunhibava S (2020) Fintech regulatory sandboxes in Australia and Malaysia: a legal analysis. IIUM Law Journal

27 Khraisha T, Arthur K (2018) Can we have a general theory of financial innovation processes? A conceptual review. Financial Innovation

28 Kumar P, Turnbull SM (2008) Optimal patenting and licensing of financial innovations. Management Science

29 Laidroo L, Avarmaa M (2019) The role of location in fintech formation. Entrepreneurship and Regional Development

30 Macchiavello E (2017) Financial-return crowdfunding and regulatory approaches in the shadow banking, fintech and collaborative finance era. European Company and Financial Law Review

31 Martinez-Climent C, Zorio-Grima A, Ribeiro-Soriano D (2018) Financial return crowdfunding: literature review and bibliometric analysis. International Entrepreneurship and Management Journal

32 McDonald R, Gao C (2019) Pivoting isn't enough? managing strategic reorientation in new ventures. Organization Science

33 Redmond W (2013) Financial innovation, diffusion, and instability. Journal of Economic Issues

34 Ringe W, Ruof C. (2020) Regulating fintech in the EU: the case for a guided sandbox. European Journal of Risk Regulation

35 Siciliani, P (2019) The disruption of the prudential regulatory framework. Journal of Financial Regulation

36 Van Loo R (2018) Making innovation more competitive: the case of fintech. UCLA Law Review

37 Vucinic M (2020) Fintech and financial stability potential influence of fintech on financial stability, risks and benefits. Journal of Central Banking Theory and Practice

38 Wu YT (2017) FinTech innovation and anti-money laundering compliance. National Taiwan University Law Review

$39 \mathrm{Xu}$ DQ, Ge MY (2017) Equity-based crowdfunding in china: beginning with the first crowdfunding financing case. Asian Journal of Law and Society

40 Yang D, Li, M (2018) Evolutionary approaches and the construction of technology-driven regulations. Emerging Markets Finance and Trade

41 Zhang N, Wang WY (2019) Research on balance strategy of supervision and incentive of P2P lending platform. Emerging Markets Finance and Trade

42 Ahern, DM (2020) Regulators nurturing fintech innovation: global evolution of the regulatory sandbox as opportunity based regulation. European Banking Institute

43 Cornelli G, Doerr S, Gambacorta L, Merrouche O (2020) Inside the regulatory sandbox: effects on fintech funding. Bank for International Settlements

44 Fenwick M, Van Uytsel S, Ying B, eds. (2020) Regulating fintech in Asia: global context, local perspectives. Springer

45 Fenwick M, Vermeulen EP (2020) Banking and regulatory responses to fintech revisited building the sustainable financial service 'ecosystems' of tomorrow. Singapore Journal of Legal Studies

46 Goo JJ., Heo, J-Y (2020) The impact of the regulatory sandbox on the fintech industry, with a discussion on the relation between regulatory sandboxes and open innovation. Journal of Open Innovation: Technology, Market, and Complexity

47 Mention A-L (2020) The age of fintech: implications for research, policy and practice. The Journal of FinTech

48 Alaassar A, Mention AL, Aas, TH (2021b) Ecosystem dynamics: exploring the interplay within Fintech entrepreneurial ecosystems. Small Business Economics

49 Brown E, Piroska D (2021) Governing fintech and fintech as governance: the regulatory sandbox, riskwashing, and disruptive social classification. New Political Economics 
\# Author/Date/Title/Outlet (\#1-41 from WoS; \#42-56 first sourced from Google Scholar)

50 Hendershott T, Zhang X, Zhao JL, Zheng Z (2021) FinTech as a game changer: overview of research frontiers. Information Systems Research

51 Hendrikse R, Bassens D, Van Meeteren M (2018) The Appleization of finance: charting incumbent finance's embrace of fintech. Finance and Society

52 Kapsis I. (2020) A truly future-oriented legal framework for fintech in the EU. European Business Law Review

53 Klus MF, Lohwasser TS, Holotiuk F, Moormann J (2019) Strategic alliances between banks and fintechs for digital innovation: motives to collaborate and types of interaction. The Journal of Entrepreneurial Finance

54 Nicoletti B (2017) The future of fintech. Palgrave Macmillan

55 Sinha S (2017) A glimpse into the world of fintech accelerators? The Open Vault at OCBC. IEEE Potentials

56 Tanda A, Schena CM (2019) FinTech, BigTech and banks: digitalisation and its impact on banking business models. Springer

Acknowledgements This research has received funding from the Horizon 2020 Programme of the European Union within the OpenInnoTrain project under grant agreement no. 823971. The content of this publication does not reflect the official opinion of the European Union. Responsibility for the information and views expressed in the publication lies entirely with the author(s).

Funding Open Access funding enabled and organized by CAUL and its Member Institutions.

\section{Declarations}

Conflict of interest The authors declare that they have no conflict of interest.

Open Access This article is licensed under a Creative Commons Attribution 4.0 International License, which permits use, sharing, adaptation, distribution and reproduction in any medium or format, as long as you give appropriate credit to the original author(s) and the source, provide a link to the Creative Commons licence, and indicate if changes were made. The images or other third party material in this article are included in the article's Creative Commons licence, unless indicated otherwise in a credit line to the material. If material is not included in the article's Creative Commons licence and your intended use is not permitted by statutory regulation or exceeds the permitted use, you will need to obtain permission directly from the copyright holder. To view a copy of this licence, visit http://creativecommons.org/licen ses/by/4.0/.

\section{References}

Adams RJ, Smart P, Huff AS (2017) Shades of grey: guidelines for working with the grey literature in systematic reviews for management and organizational studies. Int J Manag Rev 19(4):432-454. https://doi.org/10.1111/ijmr.12102

Ahern, DM (2020) Regulators nurturing fintech innovation: global evolution of the regulatory sandbox as opportunity based regulation. European Banking Institute Working Paper Series No. 60. Frankfurt: European Banking Institute. http://ijlt.in/wp-content/uploads/2020/11/IJLT-152-91-124.pdf

Alaassar A, Mention AL, Aas TH (2020) Exploring how social interactions influence regulators and innovators: the case of regulatory sandboxes. Technol Forecast Soc Change. https://doi.org/10.1016/j. techfore.2020.120257

Alaassar A, Mention AL, Aas TH (2021a) Exploring a new incubation model for FinTechs: regulatory sandboxes. Technovation 103:102237. https://doi.org/10.1016/j.technovation.2021.102237 
Alaassar A, Mention AL, Aas TH (2021b) Ecosystem dynamics: exploring the interplay within Fintech entrepreneurial ecosystems. Small Bus Econ. https://doi.org/10.1007/s11187-021-00505-5

Allen F, Goldstein I, Jagtiani J, Lang WW (2016) Enhancing prudential standards in financial regulations. J Financial Serv Res 49(2-3):133-149. https://doi.org/10.1007/s10693-016-0253-2

Allen HJ (2019) Regulatory sandboxes. George Wash Law Rev. 87(3):579-645

Arner DW, Barberis J, Buckley RP (2015) The evolution of Fintech: a new post-crisis paradigm. Georget J Int Law 47:1271-1315

Arner DW, Barberis J, Buckley RP (2016) 150 Years of Fintech: an evolutionary analysis. JASSA 3:2229. https://doi.org/10.3316/informit.419780653701585

Arthur KNA (2017) Financial innovation and its governance: cases of two major innovations in the financial sector. Financ Innov 3:10. https://doi.org/10.1186/s40854-017-0060-2

Bavoso V (2020) The promise and perils of alternative market-based finance: the case of P2P lending in the UK. J Bank Reg 21(4):395-409. https://doi.org/10.1057/s41261-019-00118-9

Belderbos R, Grabowska M, Leten B, Kelchtermans S, Ugur N (2017) On the use of computer-aided text analysis in international business research. Glob Strat J 7(3):312-331. https://doi.org/10.1002/gsj. 1162

Bergek A, Norrman C (2008) Incubator best practice: a framework. Technovation 28(1-2):20-28. https://doi.org/10.1016/j.technovation.2007.07.008

Berman A, Cano-Kollmann M, Mudambi R (2021) Innovation and entrepreneurial ecosystems: fintech in the financial services industry. Rev Manag Sci. https://doi.org/10.1007/s11846-020-00435-8

Block JH, Colombo MG, Cumming DJ, Vismara S (2018) New players in entrepreneurial finance and why they are there. Small Bus Econ 50(2):239-250. https://doi.org/10.1007/s11187-016-9826-6

Bouncken R, Kraus S (2021) Entrepreneurial ecosystems in an interconnected world: emergence, governance and digitalization. Rev Manag Sci. https://doi.org/10.1007/s11846-021-00444-1

Bouncken RB, Laudien SM, Fredrich V, Görmar L (2018) Coopetition in coworking-spaces: value creation and appropriation tensions in an entrepreneurial space. Rev Manag Sci 12(2):385-410. https://doi.org/10.1007/s11846-017-0267-7

Bouncken RB, Ratzmann M, Barwinski R, Kraus S (2020a) Coworking spaces: empowerment for entrepreneurship and innovation in the digital and sharing economy. J Bus Res 114:102-110. https://doi.org/10.1016/j.jbusres.2020.03.033

Bouncken RB, Kraus S, Martínez-Pérez JF (2020b) Entrepreneurship of an institutional field: the emergence of coworking spaces for digital business models. Int Entrep Manag J 16(4):14651481. https://doi.org/10.1007/s11365-020-00689-4

Boyer PC, Kempf H (2020) Regulatory arbitrage and the efficiency of banking regulation. J Fin Intermed 41:100765. https://doi.org/10.1016/j.jfi.2017.09.002

Brown E, Piroska D (2021) Governing fintech and fintech as governance: the regulatory sandbox, riskwashing, and disruptive social classification. New Political Econ. https://doi.org/10.1080/ 13563467.2021.1910645

Brummer C, Yadav Y (2019) Fintech and the innovation trilemma. Georget Law J 107(2):235-307

Buckley RP, Arner D, Veidt R, Zetzsche D (2020a) Building fintech ecosystems: regulatory sandboxes, innovation hubs and beyond. Washingt Univ J Law Policy 61(1):55-98

Buckley RP, Arner D, Zetzsche DA, Weber RH (2020b) The road to RegTech: the (astonishing) example of the European Union. J Bank Regul 21(1):26-36. https://doi.org/10.1057/ s41261-019-00104-1

Cornelli G, Doerr S, Gambacorta L, Merrouche O (2020) Inside the regulatory sandbox: effects on fintech funding. BIS Working Paper No. 901. Basel: Bank for International Settlements. https:// www.bis.org/publ/work901.htm

Covin JG, Rigtering JC, Hughes M, Kraus S, Cheng CF, Bouncken RB (2020) Individual and team entrepreneurial orientation: scale development and configurations for success. J Bus Res 112:112. https://doi.org/10.1016/j.jbusres.2020.02.023

Cumming DJ, Johan S, Pant A (2019) Regulation of the crypto-economy: managing risks, challenges, and regulatory uncertainty. J Risk Fin Manag 12(3):126-139. https://doi.org/10.3390/jrfm1 2030126

Deng H, Huang RH, Wu QR (2018) The regulation of initial coin offerings in China: problems, prognoses and prospects. Eur Bus Org Law Rev 19(3):465-502. https://doi.org/10.1007/s40804-018-0118-2

Dostov V, Shust P, Leonova A, Krivoruchko S (2019) "Soft law" and innovations: empirical analysis of ICO-related statements. Digit Policy Regul Governance 21(5):476-493. https://doi.org/10.1108/ dprg-03-2019-0018 
Fenwick M, Vermeulen EP (2020) Banking and regulatory responses to fintech revisited building the sustainable financial service 'ecosystems' of tomorrow. Singap J Legal Stud 2020(1):165-189

Fenwick M, Van Uytsel S, Ying B (eds) (2020) Regulating fintech in Asia: global context, local perspectives. Springer, Singapore

Financial Stability Board (2017) Financial stability implications from fintech: supervisory and regulatory issues that merit authorities' attention. http://www.fsb.org/wp-content/uploads/R270617.pdf. Accessed 7 June 2021

Fisch C (2019) Initial coin offerings (ICOs) to finance new ventures. J Bus Ventur 34(1):1-22. https://doi. org/10.1016/j.jbusvent.2018.09.007

Gaur A, Kumar M (2017) A systematic approach to conducting review studies: an assessment of content analysis in 25 years of IB research. J World Bus 53(2):280-289. https://doi.org/10.1016/j.jwb.2017. 11.003

Gazel M, Schwienbacher A (2020) Entrepreneurial fintech clusters. Small Bus Econ. https://doi.org/10. 1007/s11187-020-00331-1

Goo JJ, Heo J-Y (2020) The impact of the regulatory sandbox on the fintech industry, with a discussion on the relation between regulatory sandboxes and open innovation. J Open Innov Technol Mark Complex 6(2):43-60. https://doi.org/10.3390/joitmc6020043

Hackett SM, Dilts DM (2004) A systematic review of business incubation research. J Technol Transf 29(1):55-82. https://doi.org/10.1023/B:JOTT.0000011181.11952.0f

Haddad C, Hornuf L (2019) The emergence of the global fintech market: economic and technological determinants. Small Bus Econ 53:81-105. https://doi.org/10.1007/s11187-018-9991-x

Hanafizadeh P, Marjaie S (2020) Trends and turning points of banking: a timespan view. Rev Manag Sci 14:1183-1219. https://doi.org/10.1007/s11846-019-00337-4

Hendershott T, Zhang X, Zhao JL, Zheng Z (2021) FinTech as a game changer: overview of research frontiers. Inf Syst Res 32(1):1-17. https://doi.org/10.1287/isre.2021.0997

Hendrikse R, Bassens D, Van Meeteren M (2018) The Appleization of finance: charting incumbent finance's embrace of fintech. Fin Soc 4(2):159-180. https://doi.org/10.2218/finsoc.v4i2.2870

Hirano T, Motohashi T, Okumura K, Takajo K, Kuroki T, Ichikawa D, Ueno T (2020) Data validation and verification using Blockchain in a clinical trial for breast Cancer: regulatory sandbox. $\mathrm{J}$ Med Internet Res 22(6):e18938. https://doi.org/10.2196/18938

Hora W, Gast J, Kailer N, Rey-Marti A, Mas-Tur A (2018) David and Goliath: causes and effects of coopetition between start-ups and corporates. Rev Manag Sci 12(2):411-439. https://doi.org/10. 1007/s11846-017-0273-9

Hornuf L, Klus MF, Lohwasser TS, Schwienbacher A (2020) How do banks interact with fintech startups? Small Bus Econ. https://doi.org/10.1007/s11187-020-00359-3

Huang RH, Yang DM, Loo FFY (2020) The development and regulation of cryptoassets: Hong Kong experiences and a comparative analysis. Eur Bus Org Law Rev 21(2):319-347. https://doi.org/10. 1007/s40804-020-00174-z

Hughes M, Rigtering JC, Covin JG, Bouncken RB, Kraus S (2018) Innovative behaviour, trust and perceived workplace performance. Br J Manag 29(4):750-768. https://doi.org/10.1111/1467-8551. 12305

Ivanova P (2019) Cross-border regulation and fintech: are transnational cooperation agreements the right way to go? Unif Law Rev 24(2):367-395. https://doi.org/10.1093/ulr/unz021

Kapsis I (2020) A truly future-oriented legal framework for fintech in the EU. Eur Bus Law Rev 31(3):475-514

Khalid M, Kunhibava S (2020) Fintech regulatory sandboxes in Australia and Malaysia: a legal analysis. IIUM Law J 28(1):1-35. https://doi.org/10.31436/iiumlj.v28i1.475

Klein M, Neitzert F, Hartmann-Wendels T, Kraus S (2019) Start-up financing in the digital age-a systematic review and comparison of new forms of financing. J Entrep Finance 21(2):3

Klus MF, Lohwasser TS, Holotiuk F, Moormann J (2019) Strategic alliances between banks and fintechs for digital innovation: motives to collaborate and types of interaction. J Entrep Finance 21(1). https://digitalcommons.pepperdine.edu/jef/vol21/iss1/1

Kraus S, Breier M, Jones P, Hughes M (2019) Individual entrepreneurial orientation and intrapreneurship in the public sector. Int Entrep Manag J 15(4):1247-1268. https://doi.org/10.1007/ s11365-019-00593-6

Laidroo L, Avarmaa M (2019) The role of location in fintech formation. Entrep Reg Dev 32(7-8):555572. https://doi.org/10.1080/08985626.2019.1675777 
Leckenby E, Dawoud D, Bouvy J, Jónsson P (2021) The sandbox approach and its potential for use in health technology assessment: a literature review. Appl Health Econ Health Policy 19(6):857-869. https://doi.org/10.1007/s40258-021-00665-1

Lee I, Shin YJ (2018) Fintech: ecosystem, business models, investment decisions, and challenges. Bus Horiz 61(1):35-46. https://doi.org/10.1016/j.bushor.2017.09.003

Lerner J, Speen A, Baker M, Leamon A (2016) Financial patent quality: finance patents after State Street. Harvard Business School Working Paper Series No. 16-068. http://nrs.harvard.edu/urn-3:HUL. InstRepos:24009686

Lerner J, Tufano P (2011) The consequences of financial innovation: a counterfactual research agenda. Annu Rev Financ Econ 3(1):41-85. https://doi.org/10.1146/annurev.financial.050808.114326

Martinez-Climent C, Zorio-Grima A, Ribeiro-Soriano D (2018) Financial return crowdfunding: literature review and bibliometric analysis. Int Entrep Manag J 14(3):527-553. https://doi.org/10.1007/s11365-018-0511-X

Mention A-L (2019) The future of fintech. Res-Tech Manag 62(4):59-63. https://doi.org/10.1080/08956308. 2019.1613123

Mention A-L (2020) The age of fintech: implications for research, policy and practice. J Fintech 1(1):2050002. https://doi.org/10.1142/S2705109920500029

Mention A-L, Torkkeli M (2012) Drivers, processes and consequences of financial innovation: a research agenda. Int J Entrep Innov Manag 16(1-2):5-29. https://doi.org/10.1080/08956308.2019.1613123

Mian S, Lamine W, Fayolle A (2016) Technology business incubation: an overview of the state of knowledge. Technovation 50-51:1-12. https://doi.org/10.1016/j.technovation.2016.02.005

Miller MH (1986) Financial innovation: the last twenty years and the next. J Financ Quant Anal 21(4):459-471. https://doi.org/10.2307/2330693

Nicoletti B (2017) The future of fintech. Palgrave Macmillan, Basingstoke

O'Kane P, Smith A, Lerman MP (2021) Building transparency and trustworthiness in inductive research through computer-aided qualitative data analysis software. Organ Res Methods 24(1):104-139. https://doi.org/10.1177/1094428119865016

Pauwels C, Clarysse B, Wright M, Van Hove J (2016) Understanding a new generation incubation model: the accelerator. Technovation 50-51:13-24. https://doi.org/10.1016/j.technovation.2015.09.003

Peters L, Rice M, Sundararajan M (2004) The role of incubators in the entrepreneurial process. J Technol Transf 29(1):83-91. https://doi.org/10.1023/B:JOTT.0000011182.82350.df

Redmond W (2013) Financial innovation, diffusion, and instability. J Econ Issues 47(2):525-532. https:// doi.org/10.2753/JEI0021-3624470226

Ringe W, Ruof C (2020) Regulating fintech in the EU: the case for a guided sandbox. Eur J Risk Regul 11(3):604-629. https://doi.org/10.1017/err.2020.8

Scott SV, Van Reenen J, Zachariadis M (2017) The long-term effect of digital innovation on bank performance: an empirical study of SWIFT adoption in financial services. Res Policy 46(5):984-1004. https://doi.org/10.1016/j.respol.2017.03.010

Sinha S (2017) A glimpse into the world of fintech accelerators? The Open Vault at OCBC. IEEE Potentials 36(6):20-23. https://doi.org/10.1109/MPOT.2017.2737238

Tanda A, Schena CM (2019) FinTech, BigTech and banks: digitalisation and its impact on banking business models. Springer, Cham

Tranfield D, Denyer SP (2003) Towards a methodology for developing evidence-informed management knowledge by means of systematic review. Brit J Manag 14(3):207-222. https://doi.org/10.1111/ 1467-8551.00375

Veseli A, Moser S, Kubeczko K, Madner V, Wang A, Wolfsgruber K (2021) Practical necessity and legal options for introducing energy regulatory sandboxes in Austria. Util Policy 73:101296. https://doi. org/10.1016/j.jup.2021.101296

Vucinic M (2020) Fintech and financial stability potential influence of fintech on financial stability, risks and benefits. J Central Bank Theory Pract 9(2):43-66. https://doi.org/10.2478/jcbtp-2020-0013

Yang D, Li M (2018) Evolutionary approaches and the construction of technology-driven regulations. Emerg Mark Financ Trade 54(14):3256-3271. https://doi.org/10.1080/1540496x.2018.1496422

Zetzsche DA, Buckley RP, Barberis JN, Arner DW (2017) Regulating a revolution: from regulatory sandboxes to smart regulation. Fordham J Corp Financ Law 23:31-103

Publisher's Note Springer Nature remains neutral with regard to jurisdictional claims in published maps and institutional affiliations. 